\title{
Corrective Control through HVDC Links: A Case Study on GB Equivalent System
}

\author{
Inmaculada Martínez Sanz, Balarko Chaudhuri and Goran Strbac \\ Department of Electrical and Electronic Engineering \\ Imperial College London \\ London, United Kingdom
}

\begin{abstract}
Rapid change of active power through an LCC HVDC link could ensure transient stability of an AC system. This could be achieved by exploiting the short-term overload capability of the link. The challenge is to compute the optimum change in power order that is required as a post-contingency corrective control action in order to ensure transient stability without any prior knowledge of the contingency. In this paper the model predictive control (MPC) approach is used as it can explicitly consider the constraint on available headroom depending on the short-term overload capability of the LCC HVDC link. The effectiveness of the MPC-based corrective control scheme is demonstrated on a 3-generator equivalent of the Great Britain (GB) transmission system including the planned 2.2 GW Westcoast sub-sea LCC HVDC link under different loading scenarios and for a range of short-term overload capabilities.
\end{abstract}

Index Terms-Corrective Control, High Voltage Direct Current (HVDC), Model Predictive Control (MPC), Transient Stability, Wide-Area Measurements.

\section{INTRODUCTION}

Corrective control in power system refers to all those actions that are applied once a disturbance has occurred in the system in order to minimize its consequences [1]. These actions include generators tripping, load shedding, capacitors switching, etc. Application of these post-fault corrective control actions also know as special protection schemes (SPS) has been effective in increasing transmission network capacity [2].

High Voltage Direct Current (HVDC) links based on line commutated converter (LCC) technology allows rapid change of power flow through it which could be well beyond its rated capacity in the short time frame. This fast control and shortterm overload capability (in tens of seconds timeframe) of an LCC HVDC link could be exploited for corrective control action.

A few papers have demonstrated the use of the HVDCs capability to rapidly control its power flow to improve the system transient stability. In [3] PI controllers based on different AC variables are used to compute the HVDC power settings, whereas in [4] a step at the set point is applied after an outage is detected. Among the advanced control strategies, the model predictive control (MPC) has been applied as a real time corrective control as it can maintain an acceptable response while respecting the system constraints. The works presented in [5] and [6] are relevant to the MPC approach described in this paper. Reference [5] focuses in the MPC for the modulation of the active power through a LCC HVDC link in order to avoid or delay the loss of synchronism after a large disturbance. However, restrictive assumptions were made which include simplified dynamics of power system elements, no delays and use of an accurate system model by the MPC controller. Reference [6] sets the formulation for MPC applied to VSC-HVDC links, but the strategy is not validated for severe outage conditions. The MPC approach has been studied in detail in [7] for a robust first swing stability protection using FACTS devices, and in [8] to control a TCSC in a single machine infinite bus system. Compared with the previous work the contributions of this paper are:

- The implementation of emergency corrective control strategy based on the MPC relying on with wide-area measurements available from the two ends of the Anglo-Scottish boundary in the Great Britain (GB) equivalent system.

- Demonstrate the effectiveness of the MPC-based corrective control action through the planned Westcoast LCC HVDC link in the GB future transmission network.

- Sensitivity analysis for a range of the short-term overload capability of the LCC-HVDC using realistic future loading scenarios for the GB system and also investigating the impact of remote signal transmission delays.

The structure of this paper is as follows. First, the generic MPC formulation used for corrective control is described in Section II. Section III introduces the problems associated with power transfer across the Anglo-Scottish boundary in the GB system, the study network and the setup for the simulations. Section IV analyzes the performance of the proposed

Support from National Grid is gratefully acknowledged. 
corrective control for different loading scenarios and a range of possible short-term overload capabilities of the LCC HVDC link. Finally, Section V offers some conclusions.

\section{MODEl PREDICTIVE CONTROL (MPC) FORMULATION}

MPC is a discrete-time control strategy that adopts a receding horizon approach: at every time step $k=\Delta t$, an optimal control problem is solved, determining a control sequence that minimizes a certain cost function over a time horizon $N_{C}$. The first element of this sequence is applied and, at the next time step, the same process is repeated [9].

\section{A. Cost Function and Network Model}

The cost function of the quadratic optimization problem that is solved at each instant $k$ to determine the control input sequence over the next $N_{C}$ time steps has the following form:

$\sum_{i=0}^{N_{p}-1} \tilde{y}(k+i+1 \mid k)^{T} Q \tilde{y}(k+i+1 \mid k)+\tilde{u}(k+i \mid k)^{T} R \tilde{u}(k+i \mid k)$

with $\tilde{y}(k \mid k)=y(k \mid k)-y_{s s}, \quad \tilde{u}(k \mid k)=u(k \mid k)-u_{s s}$ and where $y(k \mid k)$ and $u(k \mid k)$ denote the vector of outputs and inputs at instant $k$, respectively, and $y_{s s}$ and $u_{s s}$, their value at steady state. $N_{P}$ is the prediction horizon for the system dynamics. The cost function weights are the diagonal positive definite matrices $Q$ and $R$. The $Q$ matrix accounts for the deviation of the output variables from their steady state value while $R$ accounts for the control effort. With the aim of minimizing the change in loading level of the critical tie-lines after a severe contingency, the voltage angles across the critical tie-corridor are the monitored system outputs that form the objective function of the MPC formulation. The power order of the LCC HVDC is the control input.

A discrete Linear Time-Invariant (LTI) model of the system is used to capture the system dynamics which are used in the optimization problem. The linearized state-space representation of the $\mathrm{n}^{\text {th }}$ order system about the nominal operating condition is as follows:

$$
\begin{gathered}
\tilde{x}(k+1)=A \tilde{x}(k)+B \tilde{u}(k) \\
\tilde{y}(k)=C \tilde{x}(k)+D \tilde{u}(k)
\end{gathered}
$$

where $\quad A \in \mathbb{R}^{n x n}, B \in \mathbb{R}^{n x 1}, C \in \mathbb{R}^{l x n}, D \in \mathbb{R}^{l x 1}$ are the system matrices. This linear model was obtained by probing the system through the HVDC link and using the system identification (N4SID) algorithm available in the identification toolbox in MATLAB. This method is well documented in [10]. The identified system was validated against the response of the original non-linear model in DIgSILENT.

In the simulations reported in this paper we have considered that the controller time step is $10 \mathrm{~ms}$, the control horizon $\left(N_{C}\right)$ and the prediction horizon $\left(N_{P}\right)$ are the same length and equal to 5 . This value was chosen to keep the computations simple. With a higher prediction horizon, the results were only marginally different from those presented here. The weight matrices were set at $Q=\left[\begin{array}{ll}1 & 0 \\ 0 & 1\end{array}\right]$ and $R=0.1$.

\section{B. Power System Constraints}

The MPC can explicitly handle constraints on the control variables [9]. Here we have only considered a restriction in the magnitude of the manipulated variable (i.e. HVDC power order), according to the short-term overload capability of the link. It is critical that the limits on the DC power injected by the HVDC, $P_{D C}{ }^{\text {lim }}$, are respected during control computations to avoid possible saturation of the actuators.

$$
\left|P_{D C}\right| \leq P_{D C}^{\lim }
$$

\section{STUDY SYSTEM AND SCENARIOS}

\section{A. Problem description}

In the GB transmission network the interconnection between Scotland and England (also known as 'AngloScottish boundary') has been identified as a critical transmission corridor. The transfer capacity is limited by angle stability considerations and is inadequate to support the projected growth in power transfer from the North to the South of the UK. This Anglo-Scottish boundary comprises two $400 \mathrm{kV}$ double-circuit corridors [11].

Currently the transfer limit is set by the N-2 security criterion to ensure secure system operation following the outage of one of the two double-circuit corridors. The support from corrective control when the outage occurs is not considered [12]. It is expected that network reinforcements, especially with the installation of series compensation, will allow each double-circuit corridor to be operated close to its thermal capacity of $4400 \mathrm{MW}$ [11]. In addition, a $2.2 \mathrm{GW}$ sub-sea LCC HVDC link would be commissioned along the west coast of UK by 2015/16 to further increase the transmission capacity between Scotland and England [13].

Rapid change of power flow through the West-coast LCC HVDC link can be used as a post-fault corrective control action to achieve even higher nominal (pre-fault) power transfers through the Anglo-Scottish boundary without compromising system security. This is illustrated in the remaining part of the paper.

\section{B. GB Equivalent Test System}

The test system used in this study is a three area network whose structure and parameters are representative of the GB power system as shown in Figure 1. This network is based upon the one described in [14] which has been adapted to correspond to a future `2015 GB-like' network model. Area 1 is closely coupled to the main system (Area 3), while Area 2 is relatively remote. They are connected to the main system, Area 3, by two double-circuit parallel tie lines, Line A and Line B. The impedances of these tie-lines have been adjusted to push the transient stability limit close to the thermal limit (4400 MW for each $400 \mathrm{kV}$ double-circuit corridor). In 
practice this will be achieved by the series compensators to be installed along the Anglo-Scottish boundary by 2015 .

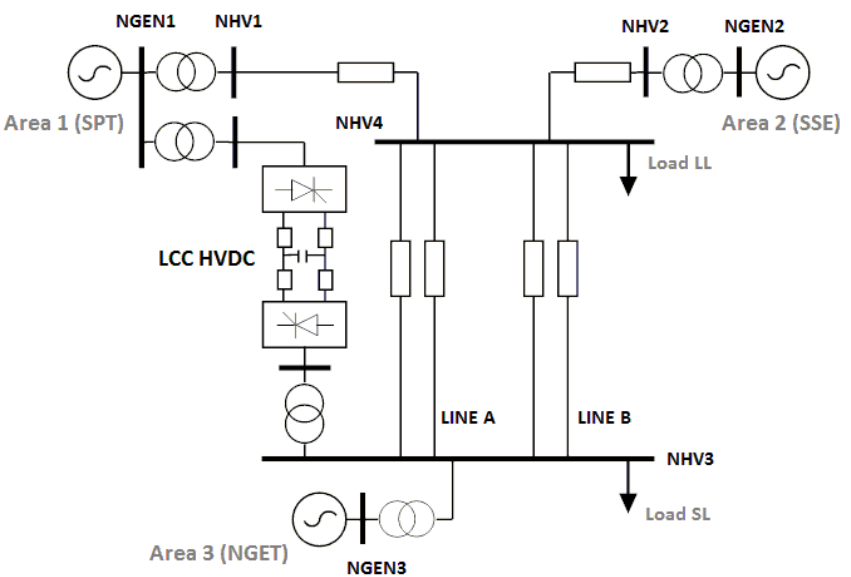

Figure 1. GB equivalent test system with an embedded LCC-HVDC link

Additionally, a LCC HVDC link is embedded within the AC system connecting generation Areas 1 and 3. This emulates the planned West-coast sub-sea link which is expected to be commissioned by $2015 / 16$. The LCC HVDC link is modelled in detail in DIgSILENT PowerFactory. The primary control loops are based on the CIGRE benchmark model [15] with the parameters adapted for a rating of $500 \mathrm{kV}^{1}$ and $2.2 \mathrm{GW}$.

Despite its simplicity, this three machine network is a reasonable representation of the dynamic behaviour of the GB system and in particular, the problems associated with high power transfer across the Anglo-Scottish boundary.

\section{Simulation Setup}

The MPC algorithm was implemented in MATLAB while the power system was simulated in DIgSILENT Power Factory. The data transfer between the two software platforms is possible through an interface in DIgSILENT, as shown in Figure 2, and takes place at each integration time step every $10 \mathrm{~ms}$.

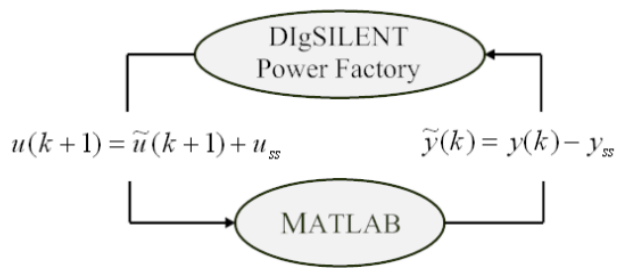

Figure 2. Simulation set up with PowerFactory and MATLAB

However, the system measurements used by the MPC controller are updated every $20 \mathrm{~ms}$ which is the typical sampling interval for the phasor measurement units (PMUs).

1 It is now known that the voltage rating for the Western dc link will be $\pm 600 \mathrm{kV}$ (http://www.westernhvdclink.co.uk/). We stick to the previous chosen value of $+500 \mathrm{kV}$ which would not affect the conclusions of this study.

\section{Simulation RESUlts}

\section{A. Different Loading Scenarios}

Three different power transfer level across the AngloScottish boundary, termed as: heavy, normal and light loading conditions (see Table I), have been considered for the case study. In all these scenarios, the DC link operates at its rated capacity, carrying $2.2 \mathrm{GW}$. The power transfer through the two AC double-circuit corridors varies.

TABLE I

CONSIDERED LOAdING SCENARIOS: POWER BEING TRANSFERRED FROM NORTH TO SOUTH

\begin{tabular}{|c|c|c|c|}
\cline { 2 - 4 } \multicolumn{1}{c|}{} & Light loading & Normal loading & Heavy loading \\
\hline Dc link & $2200 \mathrm{MW}$ & $2200 \mathrm{MW}$ & $2200 \mathrm{MW}$ \\
\hline AC lines & $3520 \mathrm{MW}$ & $4400 \mathrm{MW}$ & $4730 \mathrm{MW}$ \\
\hline Total & $\mathbf{5 7 2 0} \mathbf{M W}$ & $\mathbf{6 6 0 0} \mathbf{M W}$ & $\mathbf{6 9 3 0} \mathbf{M W}$ \\
\hline
\end{tabular}

The contingency under study is the outage of one of the two double-circuit lines $(\mathrm{N}-2)$. At $\mathrm{t}=1.0 \mathrm{~s}$ a three-phase to ground fault occurs in one of the double-circuit lines, Line B, which is cleared after $80 \mathrm{~ms}$ by disconnecting the faulted lines.

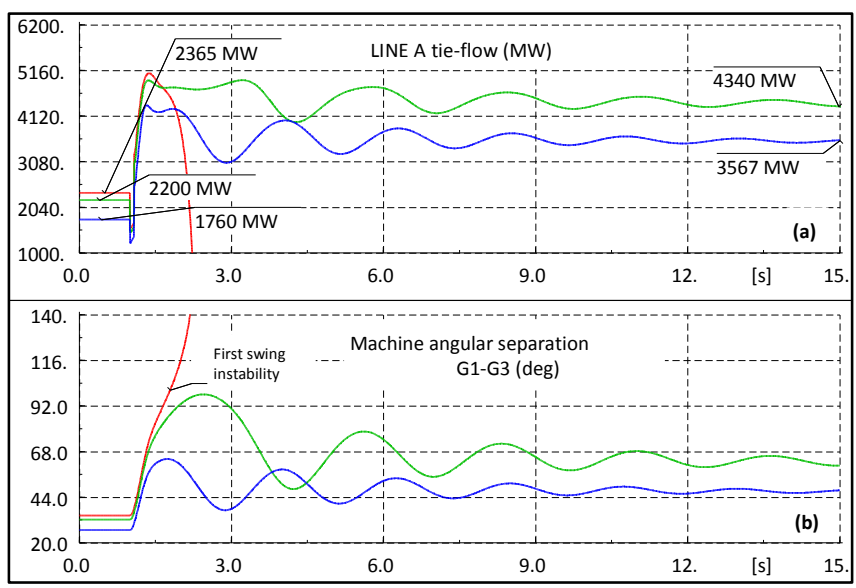

Figure 3. System dynamic response following Line B outage for heavy (red), normal (green) and light (blue) loading conditions without corrective control. (a) Power flow through Line A. (b) Angular separation between Generators 1 and 3 .

Figure 3 shows, angular separation between generators 1 and 3 and the power flow through the healthy line (Line A) without any corrective control in place. Under heavy loading (red trace), the outage of Line B leads to transient instability if the West-coast link is operated with a fixed (rated) power order of $2.2 \mathrm{GW}$. Hence, this scenario is not N-2 secure. For lower power transfers corresponding to the normal (green trace) and light loading (blue trace) scenarios, the system is secure according to the (N-2) criterion.

Figure 4 shows the simulation results following the same contingency as above, but this time with the MPC-based corrective controller in action. 


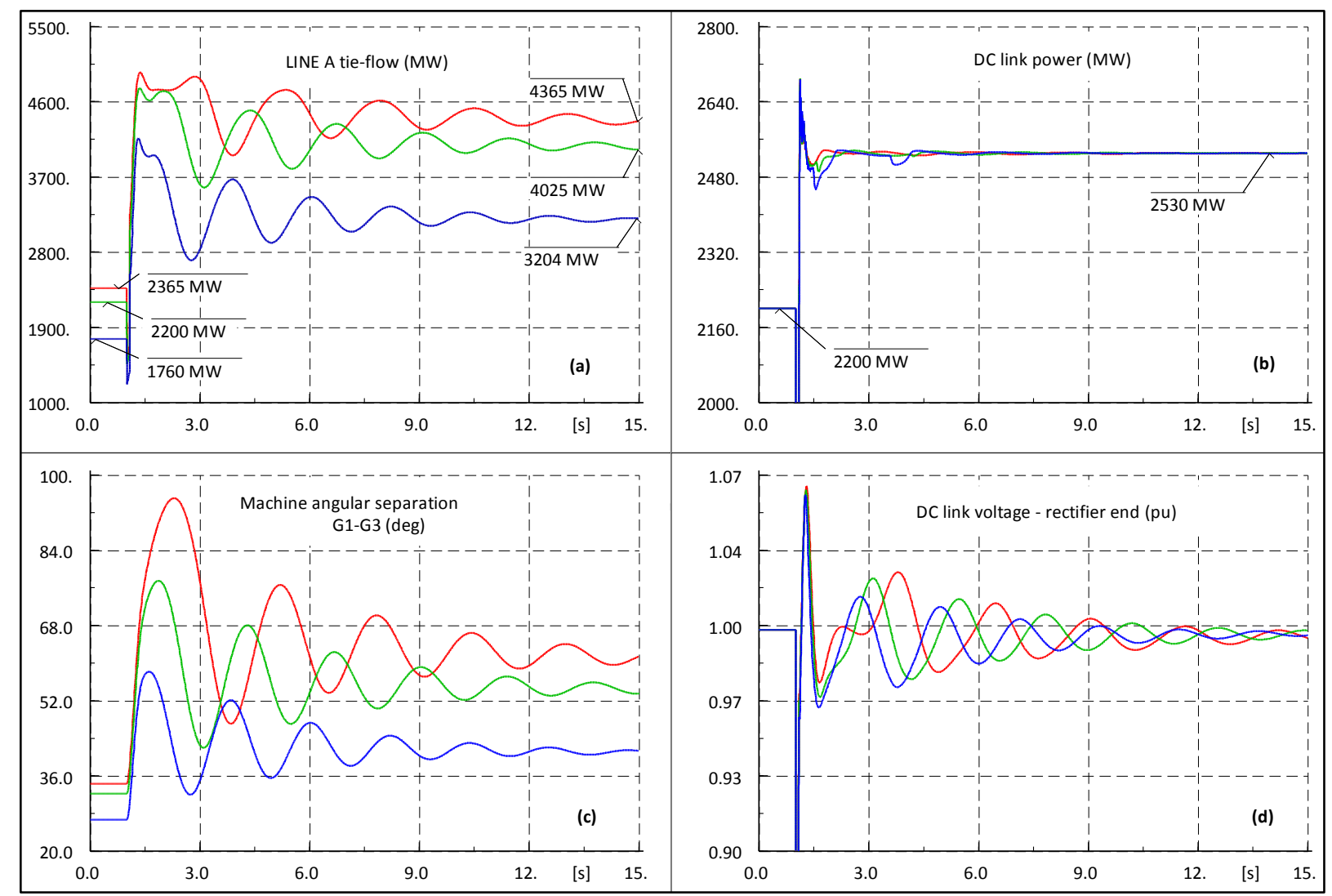

Figure 4. System dynamic response to Line B outage for heavy (red), normal (green) and light (blue) loading conditions with the MPC controller.

(a) Power through Line A. (b) Power through the DC link. (c) Angular separation between Generators 1 and 3. (d) LCC HVDC voltage at the rectifier end.

It is clear from Figure 4 that the proposed corrective control strategy is able to ensure stable post-fault operation even under heavy loading condition by exploiting the shortterm overload capability of the LCC HVDC (red traces). A $15 \%$ short-term overload capacity has been assumed, which is realistic for thyristor valves. This upper limit on dynamic variation of active power has been considered explicitly in the MPC calculations and is reflected in subplot (b) which shows the power though the DC link. The performance is also satisfactory for the normal and light loading conditions (green and blue traces). As expected, the corrective control strategy attempts to minimize the change of loading level of the double-circuit corridor in operation (Line A) following the outage of the other (Line B).

\section{B. Short-Term Overload Capability of the LCC HVDC}

The power transfer through the West-coast HVDC can be increased beyond its rated capacity $(2.2 \mathrm{GW})$ for a short period depending on different conditions like ambient temperature, availability of redundant cooling equipment, etc [16]. The impact of different levels of available short-term overload capacity of the HVDC link on the allowable nominal (pre-fault) power transfer levels across the AngloScottish boundary is summarized in Tables II and III.
TABLE II.

INFLUENCE OF THE SHORT-TERM OVERLOAD CAPABILITY OF THE LCCHVDC ON THE PERFORMANCE OF THE CORRECTIVE CONTROL FOR A HeAVy TRANSFER SCENARIO OF $6.93 \mathrm{GW}$

\begin{tabular}{|c|c|c|c|c|c|}
\hline \multirow{2}{*}{$\begin{array}{c}\text { LCC- } \\
\text { HVDC } \\
\text { short-term } \\
\text { overload } \\
\text { capability }\end{array}$} & \multicolumn{2}{|c|}{$\begin{array}{c}\text { Pre-fault power } \\
\text { transfer }(M W)\end{array}$} & \multicolumn{2}{|c|}{$\begin{array}{c}\text { Post-fault power } \\
\text { transfer }(\boldsymbol{M W})\end{array}$} & $\begin{array}{c}\text { Is the } \\
\text { system } \\
\text { stable } \\
\text { after the } \\
\text { double- } \\
\text { circuit } \\
\text { outage? }\end{array}$ \\
\hline $\mathbf{1 0 \%}$ & 2200 & 2365 & 2420 & 4510 & NO \\
\hline $\mathbf{1 5 \%}$ & 2200 & 2365 & 2530 & 4400 & YES \\
\hline $\mathbf{2 0 \%}$ & 2200 & 2365 & 2640 & 4290 & YES \\
\hline
\end{tabular}

Table II presents the results for $6.93 \mathrm{GW}$ power transferred between Scotland and England. It can be observed that a $10 \%$ overload capacity is insufficient to preserve system stability after the double-circuit outage. This is validated by the dynamic response in Figure 5 (magenta trace). Higher overload capabilities (above 15\%) provide adequate headroom for the corrective control to work satisfactorily (blue and black traces in Fig. 5). This implies that heavy loading can be supported only if there is adequate short-term overload capacity to be exploited. 


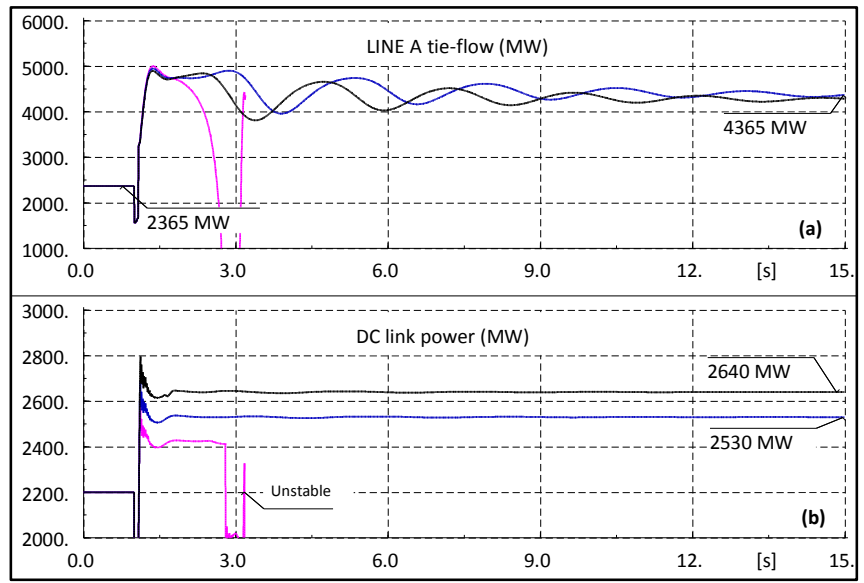

Figure 5. System dynamic response following Line B outage under heavy loading conditions with corrective controller and 10\% (magenta), $15 \%$ (blue) and 20\% (black) short-term overload capability for the LCC HVDC. (a) Power through Line A. (b) Power through the DC link.

Table III shows the results for $7.04 \mathrm{GW}$ transferred through the Anglo-Scottish boundary. For higher power transfers, the minimum overload capability required to keep the system stable with the corrective action in case of the outage of one of the AC lines is greater than before (above 20\%). The corrective control would be effective in ensuring ( $\mathrm{N}-2)$ security only if the short-term overload capability is above $20 \%$ of the rated capacity $(2.2 \mathrm{GW})$.

TABLE III.

INFLUENCE OF THE SHORT-TERM OVERLOAD CAPABILITY OF THE LCCHVDC IN THE PERFORMANCE OF THE CORRECTIVE CONTROL FOR A HEAVY TRANSFER SCENARIO OF $7.04 \mathrm{GW}$

\begin{tabular}{|c|c|c|c|c|c|}
\hline \multirow{2}{*}{$\begin{array}{c}\text { LCC- } \\
\text { HVDC } \\
\text { short-term } \\
\text { overload } \\
\text { capability }\end{array}$} & \multicolumn{2}{|c|}{$\begin{array}{c}\text { Pre-fault power } \\
\text { transfer }(M W)\end{array}$} & \multicolumn{2}{|c|}{$\begin{array}{c}\text { Post-fault power } \\
\text { transfer }(M W)\end{array}$} & $\begin{array}{c}\text { Is the } \\
\text { system } \\
\text { stable } \\
\text { after the } \\
\text { double- } \\
\text { circuit } \\
\text { outage? }\end{array}$ \\
\hline $\mathbf{1 5 \%}$ & 2200 & 2420 & 2530 & 4510 & NO \\
\hline $\mathbf{2 0 \%}$ & 2200 & 2420 & 2640 & 4400 & YES \\
\hline $\mathbf{2 5 \%}$ & 2200 & 2420 & 2750 & 4290 & YES \\
\hline
\end{tabular}

\section{Impact of Measurement Delays}

The impact that the delay in acquisition of wide-area measurements signals on the performance of the corrective control has been evaluated. There exists an intrinsic minimum delay of one PMU sampling interval, which is typically $20 \mathrm{~ms}$. The control performance was found to be satisfactory up to a delay of about $100 \mathrm{~ms}$ for the heavy loading scenario. Above $100 \mathrm{~ms}$ the adverse impact on the system performance was visible depending upon the level of power transfer.

\section{CONCLUSSIONS}

The effectiveness of an MPC-based corrective control strategy through the planned Western HVDC link in the GB system is demonstrated. The corrective control rapidly changes the power flow through the LCC-HVDC in post-fault condition to relive the burden on the $\mathrm{AC}$ tie-lines and thus ensuring system security under higher nominal (pre-fault) power transfers through the AC corridors. The maximum power that can be transferred through the parallel AC tie-lines depends on the short-term overload capability of the LCC HVDC link. Use of MPC algorithm updated with wide-area measurements is shown to exercise fast post-fault corrective control by exploiting the short-term overload capability of an LCC HVDC link which allows higher nominal power transfer through the $\mathrm{AC}$ tie-lines without compromising security.

\section{REFERENCES}

[1] L. Wehenkel and M. Pavella, "Preventive vs. emergency control of power systems," in Power Systems Conference and Exposition, 2004.IEEE PES 2004, pp. 1665-1670.

[2] V. Madani, D. Novosel, S. Horowitz, M. Adamiak, J. Amantegui, D. Karlsson, S. Imai, and A. Apostolov, "IEEE PSRC Report on Global Industry Experiences With System Integrity Protection Schemes (SIPS)," Power Delivery, IEEE Transactions on, vol. 25, no. 4, pp. 2143-2155, Oct.2010.

[3] J. Hazra, Y. Phulpin, and D. Ernst, "HVDC control strategies to improve transient stability in interconnected power systems," in PowerTech, 2009 IEEE Bucharest 2009, pp. 1-6.

[4] R. Eriksson and V. Knazkins, "On the coordinated control of multiple HVDC links," in Transmission and Distribution Conference and Exposition: Latin America, 2008 IEEE/PES 2008, pp. 1-6.

[5] Y. Phulpin, J. Hazra, and D. Ernst, "Model predictive control of HVDC power flow to improve transient stability in power systems," in Smart Grid Communications (SmartGridComm), 2011 IEEE International Conference on 2011, pp. 593-598

[6] A. Fuchs, S. Mariethoz, M. Larsson, and M. Morari, "Grid stabilization through VSC-HVDC using wide area measurements," in PowerTech, 2011 IEEE Trondheim 2011, pp. 1-6.

[7] J. J. Ford, G. Ledwich, and Z. Y. Dong, "Efficient and robust model predictive control for first swing transient stability of power systems using flexible AC transmission systems devices," IET, Generation, Transmission \& Distribution, vol. 2, no. 5, pp. 731-742, Sept.2008.

[8] S. Wagh, A. Kamath, and N. M. Singh, "Non-linear Model Predictive Control for improving transient stability of power system using TCSC controller," in $7^{\text {th }}$ Asian Control Conference, 2009, pp. 1627-1632.

[9] J. Maciejowski, Predictive Control with constraints, PrenticeHall, 2001.

[10] R. Eriksson and L. der, "Wide-Area Measurement System-Based Subspace Identification for Obtaining Linear Models to Centrally Coordinate Controllable Devices," Power Delivery, IEEE Transactions on, vol. 26, no. 2, pp. 988-997, Apr.2011.

[11] "National Electricity Transmission System (NETS) Seven Year Statement," May 2011. [Online] Available: http://www.nationalgrid.com/uk/Electricity/SYS/current/

[12] "National Electricity Transmission System Security and Quality of Supply Standard Version 2.0," Jun. 2009. [Online] Available: http://www.nationalgrid.com/NR/rdonlyres/149DEAE1-46B0-4B20BF9C-66BDCB805955/35218/NETSSQSS_GoActive_240609.pdf

[13] "Transmission Investment Incentives (TII): update on Western HVDC Link ("Western Bootstrap")," 2011. [Online] Available: http://www.ofgem.gov.uk/Networks/Trans/ElecTransPolicy/CriticalInv estments/InvestmentIncentives/

[14] O. Anaya-Lara, F. M. Hughes, N. Jenkins, and G. Strbac, "Influence of Windfarms on Power System Dynamic and Transient Stability," Wind Engineering, vol. 30, no. 2, pp. 107-127, Mar.2006.

[15] M. O. Faruque, Z. Yuyan, and V. Dinavahi, "Detailed modeling of CIGRE HVDC benchmark system using PSCAD/EMTDC and PSB/SIMULINK," Power Delivery, IEEE Transactions on, vol. 21, no. 1, pp. 378-387, Jan.2006.

[16] HVDC Classic, Siemens [Online]. Available: http://www.energy.siemens.com/mx/en/power-transmission/hvdc 